\title{
Ancient Feng Shui View of Site Construction Site Selection and Layout Study
}

\author{
Zhihua Xu \\ School of jingdezhen ceramic institute of design art, jingdezhen 333403 , China
}

Keywords: The ancient concept of feng shui, the ancient site building, site selection, layout.

\begin{abstract}
Jingdezhen porcelain production since the eastern han dynasty to song dynasty to flourish, profound changes have taken place in the yuan dynasty jingdezhen porcelain industry, due to the yuan dynasty katyn mercantilist publicizing work, attention to the jingdezhen ceramics production and trade, set up "the float saddle porcelain bureau", promote the technological progress of the industry, quality improvement and an increase in overseas trade. Of jingdezhen in yuan dynasty craftsmen artisans across many different native regional culture of jingdezhen culture industry has certain influence, including aesthetic, customs, religion, politics, technology and so on. In the Ming and qing dynasties, jingdezhen porcelain industry is no longer dependent on agriculture and cut the bottom separation, became the pillar industry of jingdezhen economy, government is increasing demand for porcelain, the continued expansion of foreign trade export porcelain appeared custom, namely according to the requirements of different countries of China, the phenomenon of export porcelain custom imperceptible to the introduction of the foreign culture of jingdezhen, and subtle influence the traditional culture of jingdezhen. Therefore, the introduction of the regional culture, a large number of migrant population move and the change of political and religious culture of the ancient intersection makes jingdezhen formed its unique style.
\end{abstract}

\section{The ancient feng shui view of traditional porcelain making workshop and the influence of the kiln housing location}

Ancient cloud: "article augury don't tip, in; medicine is not pure, good at - people; geographic not jing, house of genocide". From the perspective of metaphysics of mysticism, feng shui is when admitted that heaven, earth, and people, the house, the grave under the premise of interactive dynamic unity, to determine the person's current situation, future and offspring's future environment and meeting and YangZhai optimization and improvement. Feng shui is an important branch of traditional Chinese art number culture, also known as the integrity, phase curtilage, bluebird, to choose a home, landscape art, originated in the zhouyi, emphasizes the harmonious coexistence of human and nature, and advocates "live, appropriate is given priority to with the broken pieces back together", the essence of which reflects ancient Chinese people's a kind of environmental concept, the relationship between human and environment, it has to do with the world outlook of China's traditional "nature and humanity" is completely consistent. Say people who want to comply with the road, with the door however this. People only choose suitable natural environment, is good for its own survival and development.

Feng shui is an important part of Chinese traditional architectural design thought, a guiding position, is in the folk consciousness and philosophical ideas under control in order to select, build the disadvantages of the living environment and environmental assessment system. A unique cultural phenomenon of ancient buildings in China, according to qi, Yin and Yang, five elements, four spirit, gossip and other theories to choose on high ground, in order to build a kind of harmony, balance, natural and human environment, reflects the ancients rational utilization of natural ecological landscape design ideas. Fengshui theory in ancient architecture has made full use and display. Feng shui to people not only as a part of nature, the earth itself as a more rich spiritual organisms, between the parts associated with each other, mutual coordination, the organic view of nature, the earth is not only the core of feng shui thought, is also the essence of traditional Chinese architectural culture. 
Traditional architecture on the site selection and layout of courtyard group distribution, is the address of the doctrine of "feng shui". Traditional buildings are widespread "induction that between heaven and man", "the four", "said of the Yin and Yang", said of the "five elements" and so on construction consciousness; Geomantic theory in terms of landscape, pay more attention to the harmony of the human landscape and natural landscape, In terms of environment, and especially attaches great importance to the artificial environment and natural environment harmonious and unified, door its purpose is to survey the natural, natural, and moderate use and transform the door, select the create suitable for the best built environment with people, to the sum of the Yin and Yang, day in, and, the perfection of the sum of the body and mind. Site selection of feng shui concept embodied in the "surface water back mountain, negative Yin hug just" building structure, building under the environment of mountains and water, all the best combination of natural elements to form a good living environment, this is geomantic learn that "angry" beautiful land. As is known to all, most areas in China belong to monsoon climate, can BingDang winter cold snap back mountain, surface water can meet the summer breeze, chaoyang can strive for good sunshine, near water can facilitate the production and life. This, of course, is the best feng shui is advantageous to the ecological landscape.

According to China's traditional architecture geomantic philosophy, it is not difficult to find the traditional jingdezhen porcelain making workshop and kiln house architectural landscape design elements and the laws of nature. Jingdezhen porcelain making traditional mill, kiln room every place, is pay attention to feng shui, big to the construction site, small to the front, all according to the jingdezhen characteristics and differences of geographical environment and ecological environment. For production, living and natural be in harmony, coexistence and co-prosperity, the purpose of building built with jingdezhen regional characteristics of porcelain manufacture.

Generally speaking of jingdezhen traditional porcelain making workshop building and other ancient buildings under the influence of the traditional Chinese architectural view of feng shui, pay attention to the organic connection between man and nature and mutual inductance, so pay attention to the overall understanding the relationship between human and nature, the overall thinking. Of "water", "wind", "soil", "gas" deals with the contemporary science and pay attention to the water circulation in the earth's biosphere, atmospheric circulation, the lithosphere and soil animals vegetation ecological relationships and resources, such as processing, use showed remarkably consistent. It is guided by western traditional design concept, focus on people and neglect of the relation between man and nature environment design needs the theory of reference and self-correcting. At the same time, on site selection of architectural environment planning, natural landscape aesthetic, are of the utmost importance also pays attention to humanity beauty and environment natural minolta to building harmonious organic unification, in terms of theory and practice, showed a strong aesthetic nature, shows the distinctive characteristics of Chinese traditional culture. This will help in the contemporary traditional culture are used to design landscapes, to create a modern aesthetic and landscape of native culture lasting appeal.

From traditional jingdezhen porcelain making workshop and kiln room construction site to see, everywhere embodies the pursuit of ideal landscape feng shui. First of all, the traditional jingdezhen porcelain making workshop, and wooden house built up to the mountain and echo of far and near low mountain hill, left and right sides of the mount guard, middle part spacious flat topography, and buckling of the water, it is an ideal land. Its scientific value is: on the back of the backer, is beneficial to resist the north to the winter winds, and be helpful for the natural advantages of raw materials, fuel acquisition; Facing the water, which can accept south to summer breeze, and with the aid of water transport of raw materials and ceramic products; Chaoyang, easy to get good light, gentle slope terrace, can avoid flood waterlogging, the surrounding vegetation lush, can keep water and soil, and can adjust the climate. In addition, the concept of fengshui operator in the town, the appearance of traditional workshop building has a certain influence. Particularly noteworthy is the traditional workshop building door cover, the original town, is also a kind of operator operator town, significance of the years make it become blurred, into cosmetic decorations, become one of the constituent elements of huizhou architecture form. These characteristics of different environmental factors together, box has created an 
organic ecological environment. The rich ecological image, full of vitality, site selection, also is the modern landscape architecture design patterns in the pursue.

"Feng shui" is a kind of ancient architectural culture phenomenon unique to China, from the han to the Ming and qing dynasties has long been popular in north and south. It to Yin and Yang, five elements, gossip, "qi" in ancient China, such as view of nature as the theoretical basis, the compass, for operating tools, mixing with a lot of taboo, life of divination, astrology, etc, based on the investigation to the heaven and earth mountains and rivers, distinguishes the founder, soil and water, so as to guide people how to determine the buildings (including the grave) orientation, layout, construction and so on construction site selection and layout, help people use natural properly and get a good living environment. "Feng shui" aka kanyu, green, black, jade, to choose a home, ABU, phase, phase curtilage, figure curtilage, geography, geological and landscape of, qing capsule, etc. Overall construction site selection of theoretical generalization refers to "surface water back mountain, mountain Long Ang and show, hoses arms around, a loop," hall "wide; shuikou collection, pass through two barrier-free" etc. The "pillow mountain, water, surface screen". [Pan Gu west editor: "the ancient Chinese architectural history", the fourth volume, yuan and Ming dynasty architecture, China building industry press, 1999, p. 521.] Concept of feng shui is the ancient people and nature living in common. Every place of the ancient site, is pay attention to feng shui, big to the design of the ancient kiln site, small to kiln of the front of house. Reflected the ancient people and transform nature, use the idea behind the ceramic production, also reflected the ancient site of geographical environment characteristics and differences. Though the ancient site of the building and other architectural style is so different, but in the end, the objective is to and natural be in harmony are an organic whole, is good for production and life. This, we have to admire the ancient people use natural superb idea. This place natural high design idea, to guide the building of porcelain making landscape ecological environment construction work is very meaningful.

Feng shui view embodies the ancient people and reasonable use of natural ecological landscape design ideas. Feng shui, as a key to open the traditional architectural design ideas for, without it, to understand the structure and principles of traditional Chinese architecture, it is almost impossible. Draw lessons from traditional Chinese architectural view of feng shui, you can find the jingdezhen plate of longgang design elements of the ancient site of the ecological environment and the laws of nature, thus for future new organizational system porcelain workshop, and construction of environment construction provides objective basis for the follow. Geomantic theory is the basic orientation of the relationship between human and environment, the traditional Chinese "nature and humanity" view of the universe is completely consistent. Feng shui view emphasizes the harmony of man and nature, advocated "live, appropriate is given priority to with the broken pieces back together" means people to conform to heaven, to have a natural. People only choose suitable natural environment, is good for its own survival and development. Feng shui to people not only as a part of nature, the earth itself as a more rich spiritual organisms, between the parts associated with each other, mutual coordination, the organic view of nature, the earth is not only the core of feng shui thought, is also the essence of traditional Chinese architectural culture.

Site selection of feng shui concept embodied in the "surface water back mountain, negative Yin Yang" architectural pattern. Construction under the environment of mountains and water, and all the best combination of natural elements to form a good living environment, this is geomantic learn that "angry" beautiful land. As is known to all, most areas in China belong to monsoon climate, can BingDang winter cold snap back mountain, surface water can meet the summer breeze, chaoyang can strive for good sunshine, near water can facilitate the production and life. This, of course, is the best feng shui is advantageous to the ecological landscape.

Look from the plate of the longgang ancient site's location, everywhere embodies the pursuit of ideal landscape feng shui. First of all, from the perspective of "mountain". Plate of the location of the ancient site in longgang nature, there are endless miles of mountains, north to the south and echo low mountain hill, left and right sides of the mount guard, heavy escort, to part in hall bureau, topography and spacious, and buckling of the water, it is an ideal land. Its scientific value is: the ancient site behind the 
backer, is advantageous to the north to resist winter winds, and have the natural advantages of bamboo and wood trade; Facing the water, which can accept summer south to the cool wind, but also enjoy the farmland irrigation, bamboo and wood transport, breeding of; Chaoyang, easy to get good light and gentle slope terrace, can avoid flood waterlogging, the surrounding vegetation lush, can conserve water, maintain water and soil, and can adjust microclimate. These characteristics of different environmental factors together, has created an organic ecological environment. The rich ecological image, full of vitality, site selection, also is the modern landscape architecture design patterns in the pursue.

Secondly, from the perspective of "water". Feng shui view in the source of water is angry. The hoses through, said: "the fortunes of cave in the mountains, in the water." Single sand surrounding environment is still not enough, must also observe the status of the water. In the long-term the impergium, ancient people as a good place to lean on the water, fortune country, so the concept of fengshui in the water as more important than to find the dragon.

From the perspective of the water environment of large, longgang ancient site southeast side of the water of ChangJiang from jingdezhen, from the perspective of the water environment of plate within the site longgang, artificial lake in the western mining, natural rainfall and water storage into the lake from east to west, the water will again and ChangJiang are interlinked, plate of longgang ancient site surrounded by water, already formed mountain ring of water holding something, and plate of longgang ancient site like a neat the city, within the site plate of longgang has several groundwater to meet the drinking water. The handling of the drainage system, and on the basis of science and a beautiful story, this kind of gimmick, in "west borrow water XiDi village in the south of anhui and guo hole village" lock water for good "also can be seen.

Finally, from the perspective of "tree". Northern song dynasty Li Sicong from the integrity of the total rope mixed with books are: "trees have spirit to rongsheng can sign mountain, assistant minister zhu ZhuXi temple ZuYing, first planted wood is dry, people suspected ominous. B is not before, trees or green MAO, such as oil, and a great chief." Visible and grass planted is the "ji qi" and "wind", the source of good timber is landscape greening the environment "ji" and "dragons' den.

The ancient site good forest landscape as the judgment is one of the important conditions and living environment quality premise, it to the surrounding ecological environment protection and utilization, also reflected in the ancient site of clan ZuGui, genealogy records of the ancient site homestead when the location is very pay attention to the pursuit of forest landscape, and put the thick trees as the intelligence of children and grandchildren dignitaries, made the source of porcelain. There are all kinds of trees behind the ancient site of, formed the "blotting out the sun mountain forest", "bamboo thousand night", "the shadow of ancient wei", "south" forest landscape, etc. Therefore attaches great importance to the forest landscape, the location of the ancient buildings, greening the environment is, as the ideal environment for survival.

What can we learn from these aspects of the ancients advocates planting forest greening behavior, from a certain extent, can see dish of longgang ancient site internal tree forest protection, maintain the ecological balance of the effective mechanism. At the same time, also reflects a good understanding of the natural landscape architecture. Under the auspices of feng shui concept, respect nature, love nature, comply with the nature, use nature, landscape dependencies, and warm. Drinking water, is youdao, tillage has field, raft is a mountain. Meet the requirements of production and life, to live and work in peace and contentment, both for leisure place, reclusion and defense external distractions, are ideal habitat.

\section{Conclusion}

General speaking, therefore, jingdezhen ancient site construction and other ancient Chinese architecture influenced by traditional Chinese architectural view of feng shui, built around a feng shui mainly focus on two points:

1) Because of the feng shui pay attention to the organic connection between man and nature and 
mutual inductance, so pay attention to the overall understanding the relationship between human and nature, the overall thinking. Of "water", "wind", "soil", "gas" deals with the contemporary science and pay attention to the water circulation in the earth's biosphere, atmospheric circulation, the lithosphere and soil animals such as vegetation ecological relationship and the processing of resources, using showed remarkably consistent. It is guided by western traditional design concept, focus on people and neglect of the relation between man and nature environment design theory of needs met and self-correcting.

2) Feng shui is deeply rooted in Chinese traditional culture, on site selection of architectural environment planning, also to the natural landscape aesthetic, pay attention to humanity beauty and environment natural minolta to building a harmonious organic unification, in terms of theory and practice, showed a strong aesthetic nature, shows the distinctive characteristics of Chinese traditional culture. This will help in the contemporary traditional culture are used to design landscapes, to create a modern aesthetic taste and do not break the environment of native culture lasting appeal. Produced by different geographical environment and living habits of many typical local ecological architecture patterns, such as shaanxi caves, courtyard of north China, hakka wai floor, etc., are in and the surrounding ecological environment and under the condition of coexistence with the natural environment, a model of perfect effect, and their own style. The model can be completely borrow paradigm of the contemporary architectural environment, realize its transformation in form.

\section{Acknowledgements}

Zhihua $\mathrm{xu}$, male, $\mathrm{PhD}$, postdoctoral fellow, university of jingdezhen ceramics backbone teachers, research direction: environmental art design and theoretical study, environmental ceramic art, the Chinese stone inscription art history research. This fund projects: 1 , jiangxi social sciences planning project of the intangible cultural heritage tourism landscape design research - jingdezhen ancient kiln heritage tourism landscape, for example, the number is: 15 ys27. 2, in jiangxi province cultural department scientific research project of the jingdezhen culture industry construction under the ancient site of the landscape design research, number is: YG2014177. 3, humanities and social science in colleges and universities in jiangxi province project the regionality of humanities landscape design - to jingdezhen ancient kiln building landscape design as an example, and Numbers for: GX201529

\section{References}

[1] Xiu-mei wu "system of inheritance and change: the republic of China jingdezhen porcelain development research, Beijing: guangming daily press, 2012.

[2] Various ge armoured with "design art ten speak" jinan: shandong pictorial publishing house, 2006.

[3] Liang sicheng "Chinese architecture" Beijing: China building industry press, 2005.

[4] Dai Wu three "the well after the jinan: shandong pictorial publishing house, 2005.

[5] Chang Huaisheng building environment psychology, Beijing: China building industry press, 1990.

[6] Liu Duizhen "Chinese ancient architectural history" Beijing: China building press, 2001.

[7] Lixin li "the design of art research methods" nanjing: jiangsu phoenix publication medium group fine arts publishing house, 2010. 